\title{
RESEARCH ON THE TIME OF VISUAL MUSCULAR RESPONSE IN DIVERS DURING DIVING
}

\author{
Augustyn Dolatkowski, Kazimierz Dęga, Stanisław Klajman, Janusz Torbus
}

Department of Marine Medicine of the Military Medical Academy in Gdynia

\section{ABSTRACT}

The paper presents a continuation of studies on the influence of increased ambient pressure on the eye-muscle reflex. Using the same methods, the research was carried out in real conditions, i.e. during dives in water. Dives were performed in classical equipment with air as a breathing mix at depths of $10,20,30$ 40,50 and $60 \mathrm{~m}$. It was found that statistically significant differences in the time of eye-muscle reflexes occur during the transition from 0 to 10 , from 40 to 50 and 50 to 60 meters of overpressure. In the conclusions, it was found that the prolongation of reflex time is much greater than in hyperbaric chamber studies. As in previous studies, toxic effects of components of the breathing mixture, especially nitrogen, were considered the main cause.

Keywords: diving, eye-muscle reflex, nitrogen narcosis.

ARTICLE INFO

PolHypRes 2020 Vol. 70 Issue 1 pp. $53-58$

ISSN: $1734-7009$ elSSN: $2084-0535$

DOI: $10.2478 /$ phr-2020-0005

Pages: 6, figures: 1 , tables: 1

page www of the periodical: www.phr.net.pl

Publisher

Original article

Originally published in the Naval Health Service Yearbook Gdynia 1966

Acceptance for print in PHR: 19.09.2019 r.

Polish Hyperbaric Medicine and Technology Society 


\section{INTRODUCTION}

This study is the second part of the research conducted on the behaviour of the simple reflex time (in our case the eye-muscle reflex) in divers. In the first part, the influence of compressed air on the diver's eye-muscle reflex time was examined under model conditions in a hyperbaric chamber [3]. It was found that compressed air, due to its specific effect on the human body, causes prolongation of the eye-muscle reflex time. This elongation occurred in two stages. The first extension of this time was observed when the pressure in the chamber increased to $1 \mathrm{~atm}$ (the term atm is used in the meaning of atmospheres above atmospheric pressure, normal). This can be explained by the proportionally highest pressure/volume leap to which the examined person has been subjected. When the pressure in the chamber was further increased, an adaptation occurred, which was expressed as a shortening of the eye-muscle reflex time. This reduction was maintained to $5 \mathrm{~atm}$. When the pressure was changed to $6 \mathrm{~atm}$,, the reflex time was abruptly increased due to the narcotic effect of compressed air on the central nervous system.

The aim of the research carried out in the present study was to compare the results of observations of eyemuscle reflex time obtained under model conditions in the hyperbaric chamber with the observations of that time in real conditions, while the diver is working under water. In this environment, the diver is affected not only by compressed air, but also by other factors that may affect the progression of simple reflexes.

The specific nature of work under water in high pressure conditions makes it necessary to select candidates for this profession who demonstrate particularly high psycho-physical fitness. In the assessment of this competence, the study of simple reaction times is of great importance.

\section{RESEARCH MATERIAL METHODOLOGY}

AND

The study was carried out on 30 healthy, trained military divers aged 20 to 28 years (average age 24 years), whose length of service ranged from 1 to 9 years (on average 40 months).

The tests of the eye-muscle reflex time were carried out with the use of an instrument of our own design, adapted for testing under water. The recording accuracy was 0.002 seconds. The instrument consisted of a part which recorded the eye-muscle reflex time and a diving torch, which was used as a signalling element adapted to work under water. It was connected to the recording section by an 80 metre long electric cable used for underwater communication.

The dives were performed in the standard hard hat dive equipment of the day, the breathing mix being the air supplied from the surface. To protect against the cold, which could affect the mobility of the fingers, the diver wore a woollen glove under a thin rubber dry-glove. The diving was carried out according to the descent logic defined by the Navy tables. After reaching the depth at which the last measurement was made, the diver began to ascend. The divers were underwater for about 1.5 hours.

The tests were conducted at air temperature from $5^{\circ} \mathrm{C}$ to $13^{\circ} \mathrm{C}$ (average $8^{\circ} \mathrm{C}$ ), water temperature from $4^{\circ} \mathrm{C}$ to $6^{\circ} \mathrm{C}$ (average $4.5^{\circ} \mathrm{C}$ ) and barometric pressure from $750 \mathrm{~mm} \mathrm{Hg}$ to $768 \mathrm{~mm} \mathrm{Hg}$ (average $753 \mathrm{~mm} \mathrm{Hg}$ ).

The experiment was as follows: Prior to diving, but after the diver had put on his dive suit, the surface time of the eye-muscle reflex was recorded. The reflex speed of the diver was measured by getting him to look directly into the reflector of a dive torch he was holding in his right hand. When he observed the torch illuminating, the diver would press a button mounted on the torch and linked to a recording device that measured the speed of his reactions. Next, the time of the eye-muscle reflex was measured in the same way when the diver descended into the water to the depths of: $10 \mathrm{~m} / 1 \mathrm{~atm} /, 20 \mathrm{~m} / 2 \mathrm{~atm} /$, $30 \mathrm{~m} / 3 \mathrm{~atm} /, 40 \mathrm{~m} / 4 \mathrm{~atm} /, 50 \mathrm{~m} / 5 \mathrm{~atm} /, 60 \mathrm{~m} / 6 \mathrm{~atm} /$.

The time of the eye-muscle reflex expressed in milliseconds at particular pressure levels was subject to statistical analysis. The mean time for 30 divers at particular pressure levels and standard deviation (StDev.) from these averages were determined. The obtained results were compared against each other according to the assumptions of the Student's "t" test.

\section{RESEARCH RESULTS}

Average eye-muscle reflex times recorded in 30 divers during a dive to 60 meters are shown in Table I.

Average eye-muscle reflex times recorded in 30 divers during a dive to a depth of 60 meters

\begin{tabular}{llcccccr}
\hline $\begin{array}{l}\text { Overpressure } \\
\text { atmospheres }\end{array}$ & in & 0 & 1 & 2 & 3 & 4 & 5 \\
\hline $\begin{array}{l}\text { Average reflex time } \\
\text { in milliseconds }\end{array}$ & 213 & 271 & 259 & 263 & 272 & 301 \\
\hline StDev. & 42 & 45 & 41 & 34 & 42 & 50 \\
\hline
\end{tabular}

On the basis of calculations of the "t" value from the Student's test, it was found that statistically significant differences between the average time of the eye-muscle reflex determined at particular levels of underwater pressure occurred at the transition from surface pressure of $1 \mathrm{~atm} /$ (at the significance level of 1\%), and at the change of pressure from 4 to $5 \mathrm{~atm}$ (at the significance level of 5\%), at the transition from 5 to 6 atm (at the significance level of $1 \%$ ). A graphical representation of the average eyemuscle reflex times in 30 divers depending on the pressure increase during the dive is shown in Figure 1. 


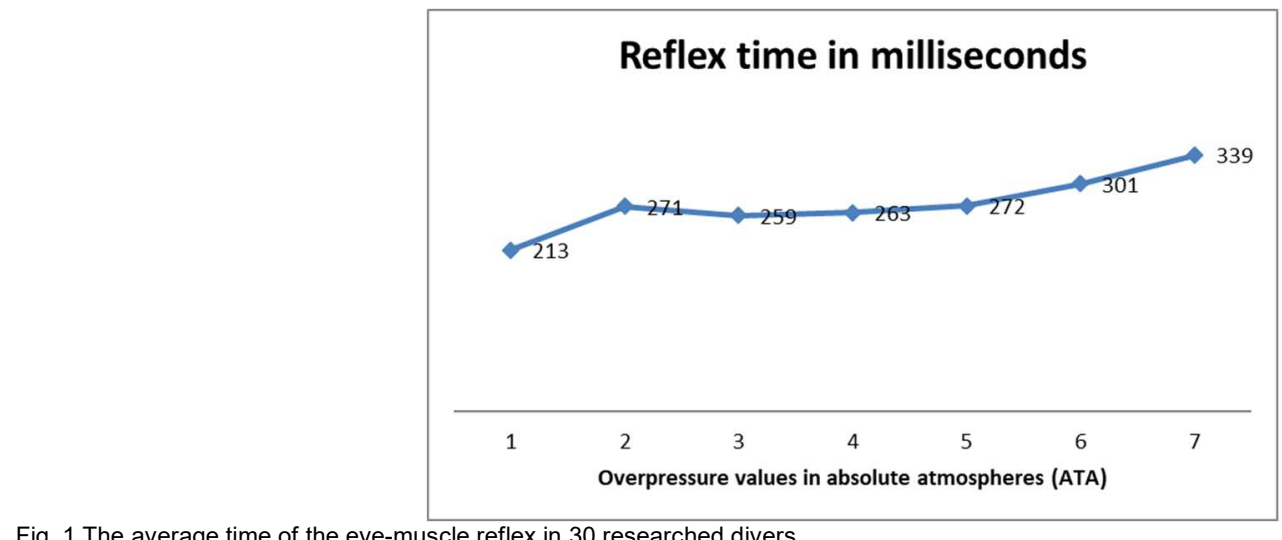

Fig. 1 The average time of the eye-muscle reflex in 30 researched divers.

\section{DISCUSSION OF RESULTS}

The diver descending underwater in classic dive equipment is influenced by various factors in addition to the specific effect of compressed air. First of all, it is important to mention the influence of deep diving on the psyche. Emotions during diving, which even a well-trained diver is not completely free of, negatively affect the activities of the second signal system in line with Pavlov's teachings. This is not without an impact on the system of simple reflexes, whose behaviour may change. At depths greater than 5-6 atm, apart from emotions, compressed air also affects the central nervous system. Its narcotic effect is associated, according to the opinions of such authors as Dolatkowski, Davis, Haldane, Huszcza, Behnke, $[1,2,4,6]$ with toxic effects of nitrogen dissolved in the organism and increasing the level of $\mathrm{CO}_{2}$, as well as disturbances in oxygen metabolism.

As our research from the previous work has shown, compressed air also influences the extension of the simple reflex time [3]. Apart from these factors, the cold, bad lighting, poor visibility and, at greater depths, total darkness, fatigue and microclimate changes within the suit during ventilation are not without significance [7]. This entire combination of factors affecting the diver during deep water diving slows down his or her reflex processes. The results of the study of the eye-muscle reflex time in divers at sea level pressure did not differ from those reported by other authors [8].

The mean of this time was within the limits obtained in the first part of these studies and amounted to $213 \mathrm{msec}$. When descending under water, the time was found to be increased at a pressure level of $1 \mathrm{~atm}$, as was observed in the model conditions in the hyperbaric chamber. Further observations showed that after a very slight and statistically unchangeable shortening of the reflex time, systematic elongation recurred. It was observed from the level of $4 \mathrm{~atm}$.

Comparing the results of tests obtained under model conditions with the results obtained in a normal diver's working environment, it can be concluded that the eye-muscle reflex time is significantly elongated, with the characteristics of this elongation similar to those obtained under model conditions in a hyperbaric chamber, primarily to $1 \mathrm{~atm}$. Subsequently, the interaction of various factors occurring in the normal working environment of the diver (emotions, microclimate changes, fatigue, etc.) does not allow for the adaptation observed in model conditions, but causes further permanent elongation of the eye-muscle reflex [7]. However, the extension of this time is particularly pronounced at 5 and 6 atm, where the above-mentioned factors are accompanied, as stated in the model experiment, by the narcotic effect of compressed air (nitrogen) on the system. Of the 30 divers observed, several showed relatively small changes in the time of the eye-muscle reflex. It should be assumed that they were particularly resistant to the negative impact of deep-water diving (nitrogen narcosis) on the body, or well trained. It seems that the selection of candidates for deepwater diving should take this psycho-physical characteristic into account. It qualifies a given diver to perform particularly difficult and responsible tasks.

\section{Conclusion}

1. The study of the eye-muscle reflex time in divers during deep-water dives showed an extension of this time.

2. The observed changes in the time of the eyemuscle reflex may indicate a decrease in the psycho-physical capacity of divers under the influence of various negative factors affecting them during deep-sea diving.

3. Some individuals were found to present no major changes in their eye-muscle reflexes during deep-water diving.

4. Testing of the psycho-physical properties of candidates for deep-water diving may allow for the selection of individuals best suited to the profession.

5. The examination of the eye-muscle reflex time under model conditions in the hyperbaric chamber can be the basis for drawing practical conclusions about the psycho-physical properties of candidates for deep-sea divers.

Paper presented at the International Oceanic Congress, Moscow 1966. 


\section{REFERENCES}

1. A.R. Behnke - Decompression sickness following exposure to high pressure. Philadelphia, London 1951;

K. Davis - Deep diving, and submarine operations. London 1951;

K. Dęga, S. Klajman, H. Mokijewski - Instrument for measuring the eye-muscle reflex time. Rocznik Słuzby Zdrowia Mar. Woj. 1964;

Dolatkowski, J. Torbus, K. Dęga - The influence of Hyperbaria on the eye-muscle reflex period at divers. Biuletyn Inst.Med.Morsk. (in print);

B.S. Haldane - Life at high pressures. London 1947;

Huszcza - Atmospheric pressure and its effect on the body. Warsaw 1951;

S. Klonowicz - Military Hygiene 100/64 Zdr.;

8. J.P. Pawłow - Twenty years of research into higher nervous function in animals. Warsaw 1952. 